\title{
MAGNETIC SOLID PHASE EXTRACTION FOR A NEW HPLC METHOD FOR THE DETERMINATION OF GEMIFLOXACIN IN HUMAN PLASMA AND BREAST MILK
}

\author{
ZEHRA DURMUS ${ }^{a}$, SERIFE EVRIM KEPEKCI TEKKELI ${ }^{* *}$, MUSTAFA VOLKAN KIZILTAS ${ }^{b}$, \\ ARMAGAN ONAL ${ }^{c}$ \\ ${ }^{a}$ Bezmialem Vakif University, Faculty of Pharmacy, Department of Pharmaceutical Biotechnology, 34093, Fatih - Istanbul - Turkey \\ ${ }^{b}$ Bezmialem Vakif University Faculty of Pharmacy, Department of Analytical Chemistry, 34093, Fatih - Istanbul - Turkey \\ 'Istanbul University, Faculty of Pharmacy, Department of Analytical Chemistry, 34116, Beyazit, Istanbul - Turkey
}

\begin{abstract}
A simple analytical procedure, magnetic solid phase extraction combination to HPLC, has been developed for the analysis of gemifloxacin in human plasma and breast milk. Before chromatographic separation, magnetic solid phase extraction has been applied for sample preparation which is currently preffered extraction technique accordingly its simple, fast and efficient procedure. $\mathrm{Fe}_{3} \mathrm{O}_{4}$ magnetic nanoparticles have been used as magnetic adsorbents, the adsorption process has been optimized. RP C18 column has been used with mobile phase composed of acetonitrile-10 mM orthophosphoric acid including $1 \mathrm{~mL} / \mathrm{L}$ triethylamine (60:40) by isocratic elution with flow rate of $1.3 \mathrm{~mL} / \mathrm{min}$. Calibration curve is linear over the range of $0.5-30 \mu \mathrm{g} / \mathrm{mL}$ and $0.5-20 \mu \mathrm{g} / \mathrm{mL}$ for plasma and breast milk, respectively. LOD and LOQ has been found to be 0.15 and $0.5 \mu \mathrm{g} / \mathrm{mL}$ for both matrices. Intraday and interday RSD values are less than $3.57 \%$ for both assays. Moreover, the newly developed method provides fast, simple, cost reduced and sensitive assay for gemifloxacin.
\end{abstract}

Keywords: HPLC, Gemifloxacin, Magnetic solid phase extraction, Plasma, Breast milk, UV detection.

\section{INTRODUCTION}

Gemifloxacin mesylate (GMX), with the chemical name 7-[(4Z)3- (aminomethyl)- 4-methoxyimino-pyrrolidin- 1-yl]-1-cyclopropyl-6fluoro- 4-oxo- 1,8-naphthyridine-3-carboxylic acid methanesulfonate, is a fluoroquinolone antibiotic (Figure 1) which is mostly used for upper respiratory tract infections [1]. GMX is excreted into breast milk [2]. Fluoroquinolones have conventionally not been used in infants but widely prescribed to nursing woman. Short-term use of GMX is acceptable in nursing mothers with monitoring the infant for possible effects such as the gastrointestinal flora injury identificated by diarrhea or diaper rash [3]. It is allowed to take one tablet of GMX as $320 \mathrm{mg}$ orally in a day, but there is no data available to recognize the effects in infants [4].<smiles>CO/C=C1\CN(c2nc3c(cc2F)c(=O)c(C(=O)O)cn3C2CC2)CC1CN</smiles>

GMX

Figure 1. Chemical structure of GMX.

In the literature there are several methods for the quantitation of GMX in human plasma [5-9] and one method in breast milk [10]. In order to separate the anayte from proteins, lipids and other matrix constituents solid-phase extraction (SPE), liquid-liquid extraction (LLE), protein precipitation techniques were used in these studies. These techniques may require evaporation of extraction solvent, dissolving the analyte, filtration, centrifugation. In the presented method magnetic solid phase extraction (MSPE) has been used. SPE has become the most commonly preffered and used isolation and enrichment technique for analytes in recent years [11]. In SPE using a variety of sorbents, it is not always possible to obtain satisfactory recovery of the analytes. Besides, the isolation and the enrichment of individual compounds can be laborious and time consuming. Taking into account the benefits resulting from the natural properties of the nanoparticles, magnetic nanoparticles (MNPs) are an alternative to conventional SPE sorbents, and they allow these limitations to be overcome. Due to their small particle size, MNPs are characterized by a high specific surface area, sorption capacity and high selectivity regarding analytes.
The use of MNPs can significantly shorten the duration of the extraction process. A small amount of sorbent enables a balance between the solid phase and sample solution. The analytes attached to adsorbent is then separated from the solution by applying an appropriate magnetic field using a magnet. Thus the phase separation can be conveniently realized and shows great advantages in separation techniques without the need for centrifugation or filtration of the sample, so contributing to a reduction in the duration of the extraction process. After adsorption, the residue can be removed easily and with a suitable solvent, desorption of the analyte is achieved $[12,13]$. This technique shows great advantages in separation in terms of rapidity, high recovery and simple procedure. Due to these advantages it is widely used in many fields including biotechnology, medicine and analytical chemistry.

In literature we see examples of MSPE applications for environmental analysis, mostly drug analysis in water samples [14-18]. Currently, it is applied for drug analysis in biological matrices [19-22]. In the proposed study a simple analytical procedure, MSPE combination to HPLC, has been developed for GMX in human plasma and breast milk.

\section{MATERIALS AND METHODS}

\subsection{Apparatus}

Structural and morphological features and thermal properties of the extraction sorbents were investigated by Fourier transform infrared spectroscopy (FT-IR), X-Ray diffractometry (XRD), high resolution transmission electron microscopy (HR-TEM). The crystallite size and phase structures of the MNPs were determined from the XRD patterns (Rigaku Smart $\mathrm{Lab}, \mathrm{Cu}-\mathrm{K}_{\alpha}$ radiation). FT-IR spectra of MNPs were recorded in transmission mode with a Bruker ATR- FT-IR infrared spectrometer, in the wave number range of 400-4000 $\mathrm{cm}^{-1}$. Magnetic properties of the MNPs were characterized by using a vibrating sample magnetometer (VSM, LDJ Electronics Inc., Model 9600 ) in an applied field of $15 \mathrm{kOe}$ at room temperature. Transmission electron microscopy (TEM) analysis was performed using a FEI Tecnai G2 Sphera microscope. A drop of diluted sample in alcohol was dripped on a TEM grid. The particle size of the magnetic nanoparticles was determined by Dynamic Light Scattering (DLS) with a Malvern Zetasizer Nano ZSP particle analyzer (Malvern Instruments Ltd., Malvern). Spectrophotometric measurements were carried out using a Shimadzu UV-160 A spectrophotometer with $1 \mathrm{~cm}$ glass cells to obtain the spectrum of GMX. pH measurements were made with WTW pH 526 digital pH Meter. The HPLC analyses were carried out on a Shimadzu (Japan) LC 20 liquid chromatograph which consisted of a LC-20AT pump, SIL AT-HT autosampler part, a SPD-20A HT UV detector at $272 \mathrm{~nm}$ and CTO 10 AC column oven and GL Sciences (Japan) C18 (ODS) column 4.6 mm I.D, 250 $\mathrm{mm}$ length and $5 \mu \mathrm{m}$ particle size. Water was purified by an aquaMAXTMultra system (Younglin Instruments, Anyang, Korea). 


\subsection{Chemicals and solutions}

Analytical grade, iron (III) nitrate nonahydrate $\left(\mathrm{Fe}\left(\mathrm{NO}_{3}\right)_{3} \cdot 9 \mathrm{H}_{2} \mathrm{O}\right)$, iron (II) nitrate tetrahydrate, $\left(\mathrm{Fe}\left(\mathrm{NO}_{3}\right)_{2} \cdot 4 \mathrm{H}_{2} \mathrm{O}\right)$, ammonia solution $\left(\mathrm{NH}_{3}, 28 \%\right)$, hydrochloric acid $(\mathrm{HCl}, 37 \%)$, were purchased from Merck (Germany). All chemicals were used as-received without purification.

GMX was obtained from Abdi Ibrahim Pharmaceuticals (Istanbul, Turkey) and its pharmaceutical preparation (Factive Tablet ${ }^{\circledR}$, Abdi Ibrahim Pharmaceuticals, Istanbul, Turkey), containing $320 \mathrm{mg}$ of GMX per tablet was purchased. Acetonitrile, phosphoric acid, and triethylamine were HPLC grade, and all the other solvents and reagents were analytical grade from Merck (Germany). A stock solution of GMX containing $0.1 \mathrm{mg} / \mathrm{mL}$ (calculated as free base) was prepared in water and diluted further with the water to obtain standard solution 0.1 to $50 \mu \mathrm{g} / \mathrm{mL}$.

\subsection{Synthesis of $\mathrm{Fe}_{3} \mathrm{O}$, nanoparticles}

Stoichiometric amount of Fe (III) and Fe (II) salts, (molar ratio of 2:1) were dissolved in $100 \mathrm{~mL}$ of distilled water under a vigorous stirring. Then an ammonia solution was added gradually until the $\mathrm{pH}$ value of $\sim 11$ and the formation of black suspension. The suspension was then refluxed at $90^{\circ} \mathrm{C}$ for $12 \mathrm{~h}$, under a vigorous stirring and under inert atmosphere (Ar). MNPs were separated from the aqueous solution by magnetic decantation, washed with excess of distilled water several times and then dried in an oven overnight.

\subsection{Sample preparation}

Venous blood samples were collected from peripheral veins of a volunteer (informed consent form was obtained according to ethical commitee approval) into tubes containing disodium EDTA and centrifuged at $4500 \times \mathrm{g}$ for $10 \mathrm{~min}$. The resultant plasma samples were stored at $-20^{\circ} \mathrm{C}$. Breast milk samples were collected from a 35 years old volunteer mum (informed consent form was obtained according to ethical commitee approval) into polyethylene storage packs. The milk samples were stored at $-20^{\circ} \mathrm{C}$. To extract the drug from the milk samples, MSPE technique was used. $0.1 \mathrm{~g} \mathrm{Fe}_{3} \mathrm{O}_{4}$ particles were added to $1 \mathrm{~mL}$ plasma and milk samples and mixed using a vortex mixer at moderate speed for $5 \mathrm{~min}$. By using a magnet the particles accumulated one side of the test tube and the supernatant was drained easily. Subsequently, $\mathrm{Fe}_{3} \mathrm{O}_{4}$ particles were washed with $1 \mathrm{~mL}$ acetonitrile and drug eluted with the solvent. Due to the fact that each magnetic particle behave like a magnet, these particles show aggregation and precipitation. For that reason before measurement, the solution was filtered to remove this precipitated section through a $0.45 \mathrm{~mm}$ filter. The filtered drug solution in acetonitrile $(20 \mu \mathrm{L})$ was injected to the HPLC system. The experimental process was schematized in Figure 2. To get higher recovery optimization studies were conducted. $\mathrm{pH}$, magnetite amount, volume of extracted plasma and milk, mixing time for adsorption, desorption solvent type, amount of desorption solvent were the tested parameters. Besides, pure magnetite and magnetited attached on graphen surface also trialed in order to find out the efficient form of the adsorbent.
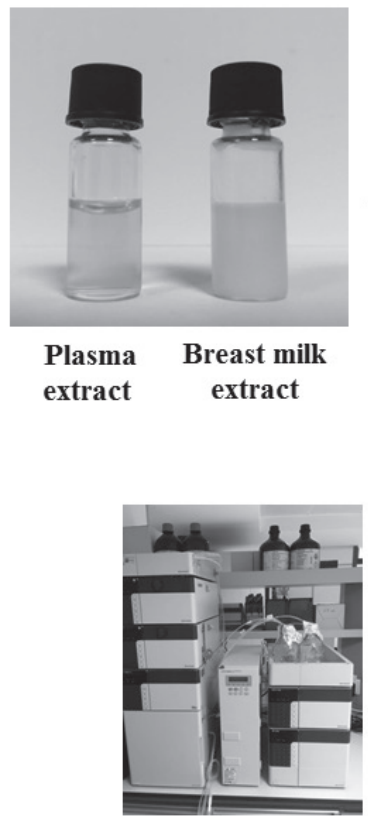

Analysis
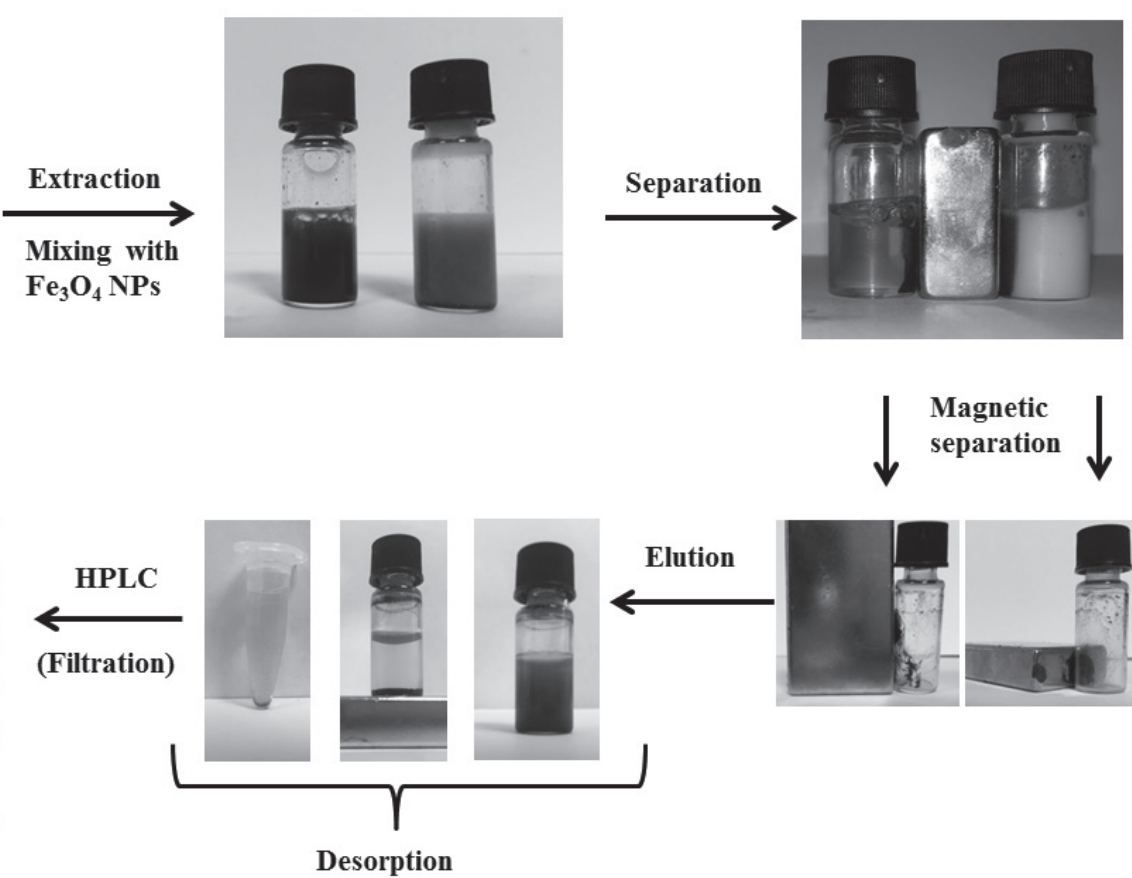

Magnetic separation

Figure 2. The experimental process of the proposed assay.

\section{RESULTS AND DISCUSSION}

3.1. Structural and morphological characterization of $\mathrm{Fe}_{3} \mathrm{O}_{4}$ nanoparticles

FT-IR spectra of $\mathrm{Fe}_{3} \mathrm{O}_{4}$ nanoparticles are given in Figure 3A. The two broad peaks appeared at about $3400 \mathrm{~cm}^{-1}$ and $600 \mathrm{~cm}^{-1}$ in the FTIR spectrum of magnetite indicate the characteristic $-\mathrm{OH}$ and $\mathrm{Fe}-\mathrm{O}$ bands, respectively. The characteristic octahedral and tetrahedral metal-oxygen stretching peaks are overlapped in this spectrum which are commonly observed at $600-400 \mathrm{~cm}^{-1}$ wavenumber region.

Figure $3 \mathrm{~B}$ shows the XRD patterns of $\mathrm{Fe}_{3} \mathrm{O}_{4}$ nanoparticles. All the observed peaks were matched well with the standard XRD patterns of $\mathrm{Fe}_{3} \mathrm{O}_{4}$ (JCPDS No. 19-629). It is clear that only the phase of $\mathrm{Fe}_{3} \mathrm{O}_{4}$ is detectable indicating that nanoparticles were pure enough. The mean size of the crystallites was estimated from the diffraction pattern by line profile fitting. The line profile, shown in Figure 3B was fitted for observed six peaks with the following miller indices: (220), (311), (400), (422), (511) and (440). The average crystallite size, $D$ and $\sigma$, was obtained as $10 \pm 2 \mathrm{~nm}$ as a result of this line profile fitting.

The size and morphology of $\mathrm{Fe}_{3} \mathrm{O}_{4}$ nanoparticles were analyzed with TEM and images of particles are given in Figure 4. One can easily notice in this figure that the nanoparticles are quite small by considering the given scale bars in the images. The average particle size of $\mathrm{Fe}_{3} \mathrm{O}_{4}$ was calculated as about $11 \pm 2 \mathrm{~nm}$ It is worthwhile to note that the size distribution is $10+2 \mathrm{~nm}$ which matches the calculated value by the Scherrer equation and the result of the XRD. The selected area electron diffraction pattern (SAED) in given inset of Figure $3 \mathrm{~A}$ of $\mathrm{Fe}_{3} \mathrm{O}_{4}$ nanoparticles shows a characteristic polycrystalline diffraction pattern of magnetite particles. 

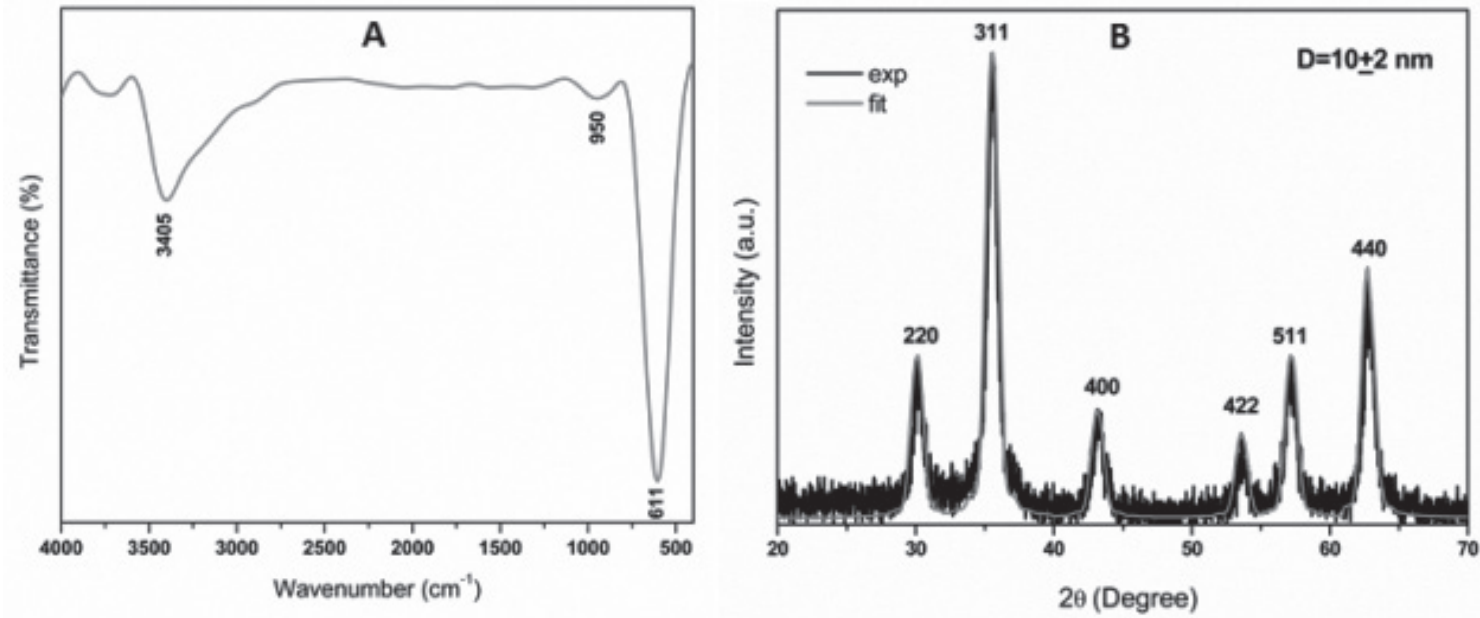

Figure 3. A) FT-IR spectra and B) XRD patterns of $\mathrm{Fe}_{3} \mathrm{O}_{4}$ nanoparticles.
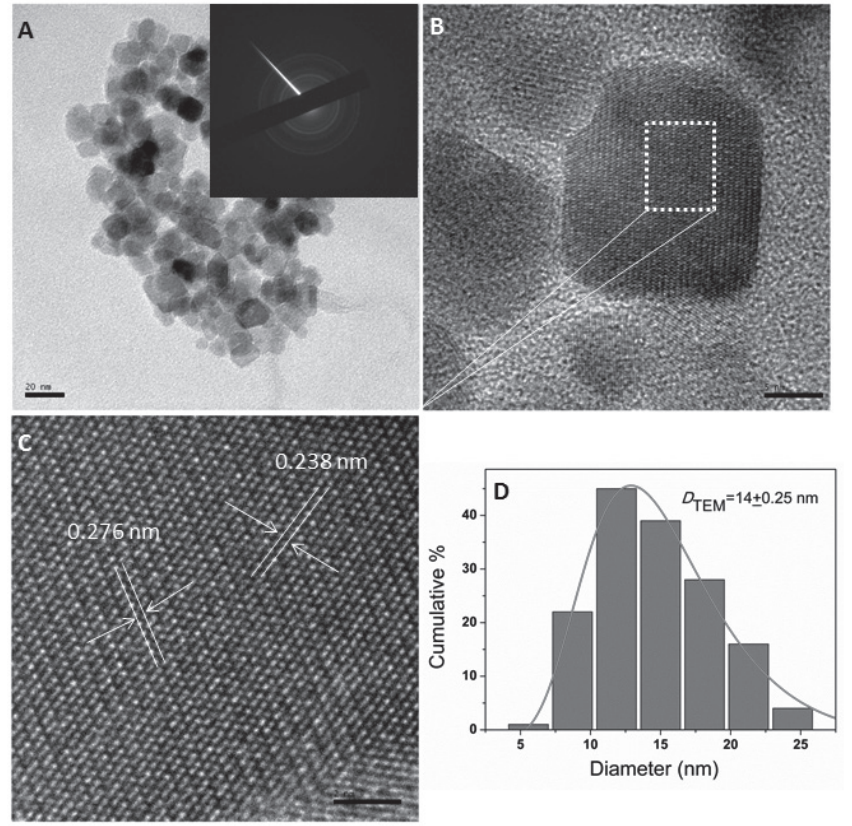

Figure 4. A) A typical TEM image and SAED pattern (inset), B) HRTEM image of an $\mathrm{Fe}_{3} \mathrm{O}_{4}$ nanocube C) HRTEM image recorded from the rectangular part of nanocube in Figure 4B and D) Calculated histogram from several TEM images with log-normal fitting.

Figure 5 shows that the magnetization increases with the applied field, whereas it does not reach to saturation even at maximum field of $15 \mathrm{kOe}$ at room temperature. In this case, the saturation magnetization $(M \mathrm{~s})$ value can be calculated by the extrapolation of $\mathrm{M}-1 / \mathrm{H}$ curve for $1 / \mathrm{H} \rightarrow 0$. The $M \mathrm{~s}$ value of $\mathrm{Fe}_{3} \mathrm{O}_{4}$ nanoparticles was found to be $65 \mathrm{emu} / \mathrm{g}$. This situation is expected phenoma for the hybrid nanoparticle systems and explained by the difference in spin ordering at the surface of the particles over that in the bulk resulting a magnetic core-shell structure. The weaker magnetization and lack of saturation are characteristic features of superparamagnetic particles having the smaller grain size than $20 \mathrm{~nm}$ (23). Magnetization of these nanoparticles can be described by the Langevin function and average particle size can be determined by theoretical fitting of this function to experimental $(\mathrm{M}-\mathrm{H})$ curves. By taking into account of the $M \mathrm{~s}$ value of $\mathrm{Fe}_{3} \mathrm{O}_{4}$ particles, $65 \mathrm{emu} / \mathrm{g}$, the average particle size can be determined as $10.60 \mathrm{~nm}$.

Hydrodynamic sizes of MNPs were determined by dynamic light scattering (DLS) which are shown in (Figure 6). It is clear that this hydrodynamic diameter was larger than the particle size determined from TEM and XRD analysis.
With respect to the magnetization relaxation theory of superparamagnetic nanoparticles, increase in hydrodynamic volume extends the duration of Brownian relaxation while the relaxation via Nèel mechanism is unaffected. DLS measurements indicate increase in hydrodynamic volume (intensity) or potential agglomeration of magnetic nanoparticles because of the blocking of Brownian relaxation contribution (24).

\subsection{Optimization of MSPE parameters}

$\mathrm{pH}$, magnetite amount, volume of extracted plasma and milk, mixing time for adsorption, desorption solvent type, amount of desorption solvent, magnetite form as pure particles or attachments on graphen surface were trialed for both matrices. By using $20 \mathrm{mM}$ phosphate buffer solution (PBS, pH 3.0) and with $0.1 \mathrm{M}$ borate buffer $(\mathrm{pH} \mathrm{9})$ acidic and basic medium were achieved and the adsorption efficiency was lower in these mediums than plasma $\mathrm{pH} 7.4$ and $\mathrm{pH}$ of milk $\sim 6.8$ respectively.

The required MNPs amount was determined by testing $0.05-0.5 \mathrm{~g}$ of magnetite. $4.31 \times 10^{-4}$ mole $(0.1 \mathrm{~g}) \mathrm{Fe}_{3} \mathrm{O}_{4}$ addition was found out as optimum amount. 

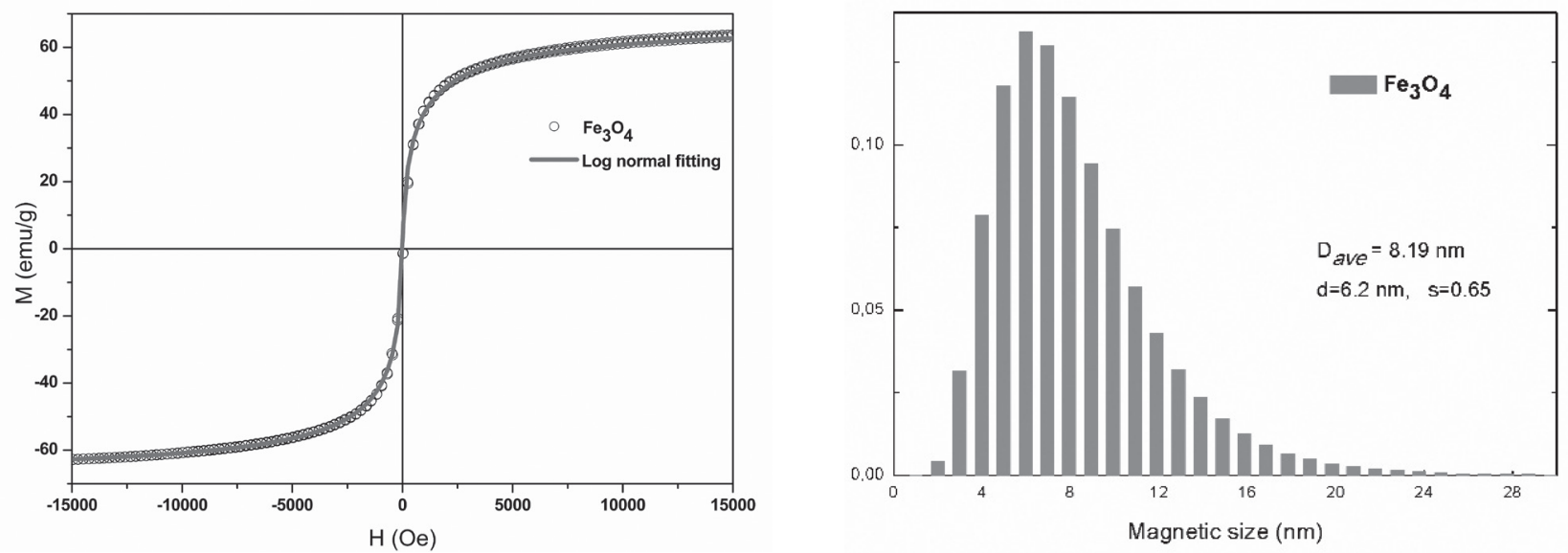

Figure 5. A) Magnetic hysteresis loop and B) magnetic size histogram of $\mathrm{Fe}_{3} \mathrm{O}_{4}$ nanoparticles at room temperature.

A

Size Distribution by Intensity

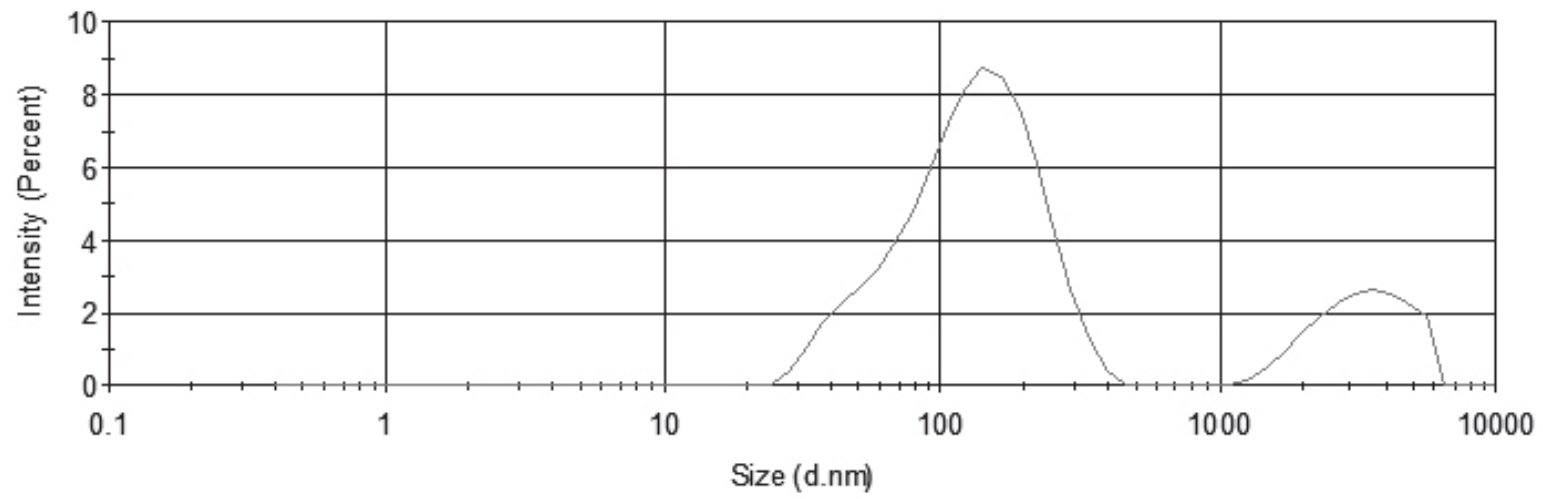

B

Size Distribution by Number

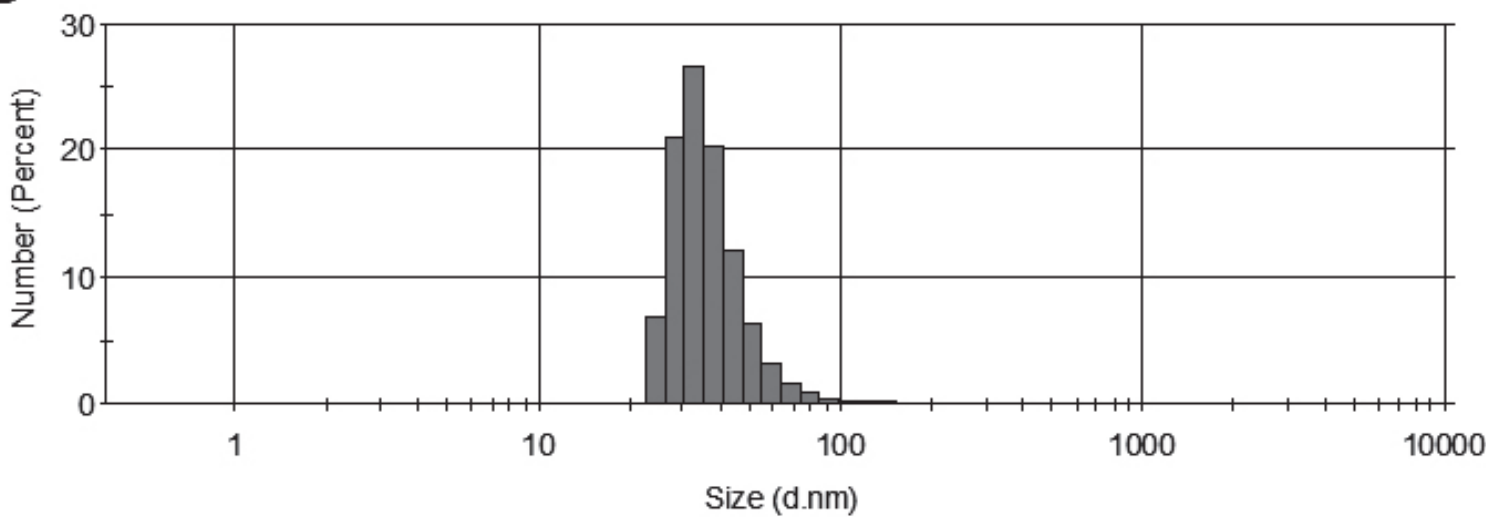

Figure 6. Size distribution a) intensity graph and b) number graph of $\mathrm{Fe}_{3} \mathrm{O}_{4}$ nanoparticle as revealed by DLS.

According to mol ratio method, the stochiometry of the adsorption process was determined. Moles of $\mathrm{Fe}_{3} \mathrm{O}_{4}$ was held constant, while the amount of drug is varied. Different mole ratios $\left(\mathrm{Fe}_{3} \mathrm{O}_{4} / \mathrm{GMX}\right)$ were trialed in the range of $10-250$. 100 fold of magnetite was found optimum.

Different volumes of plasma and milk was trialed from 0.1-5 mL, extraction from $1 \mathrm{~mL}$ was found as optimum volume. Mixing for $5 \mathrm{~min}$ was also find as the optimum duration between 1-7 min. time intervals.

In order to achieve high recovery different desorption solvents were trialed such as ethanol, methanol, acetone, ethylacetate and acetonitrile. Maximum recovery was observed with acetonitrile which is also consistent with the mobile phase and $1 \mathrm{~mL}$ was adequate to reach a high recovery. Figure 7 shows the effects of $\mathrm{pH}$, magnetite concentration and desoption solvent type, the values are indicated on average for both matrices.

\subsection{Chromatographic process}

Various mobile phase and column type and size combinations were tested with different flow rates and column temperatures. According to the non polar structure of drug substance, RP HPLC was preffered and C18 (ODS) column 
(4.6 $\mathrm{mm}$ I.D, $250 \mathrm{~mm}$ length and $5 \mu \mathrm{m}$ particle size) was used. The mobile phase was acetonitrile-10 mM orthophosphoric acid (pH 6) including $1 \mathrm{~mL} / \mathrm{L}$ triethylamine $(60: 40 \mathrm{v} / \mathrm{v})$ with a flow rate of $1.3 \mathrm{~mL} / \mathrm{min}$ were used with isocratical elution profile. The column temperature was set at $40^{\circ} \mathrm{C}$ to achieve the optimum resolution value of the chromatograms. The retantion time is about $2.7 \mathrm{~min}$. For both matrices. The chromatograms for blank and $10 \mu \mathrm{g} /$ mL GMX in plasma and milk are showed in Figure 8 and the system suitability parameters of the chromatograms are listed in Table 1.
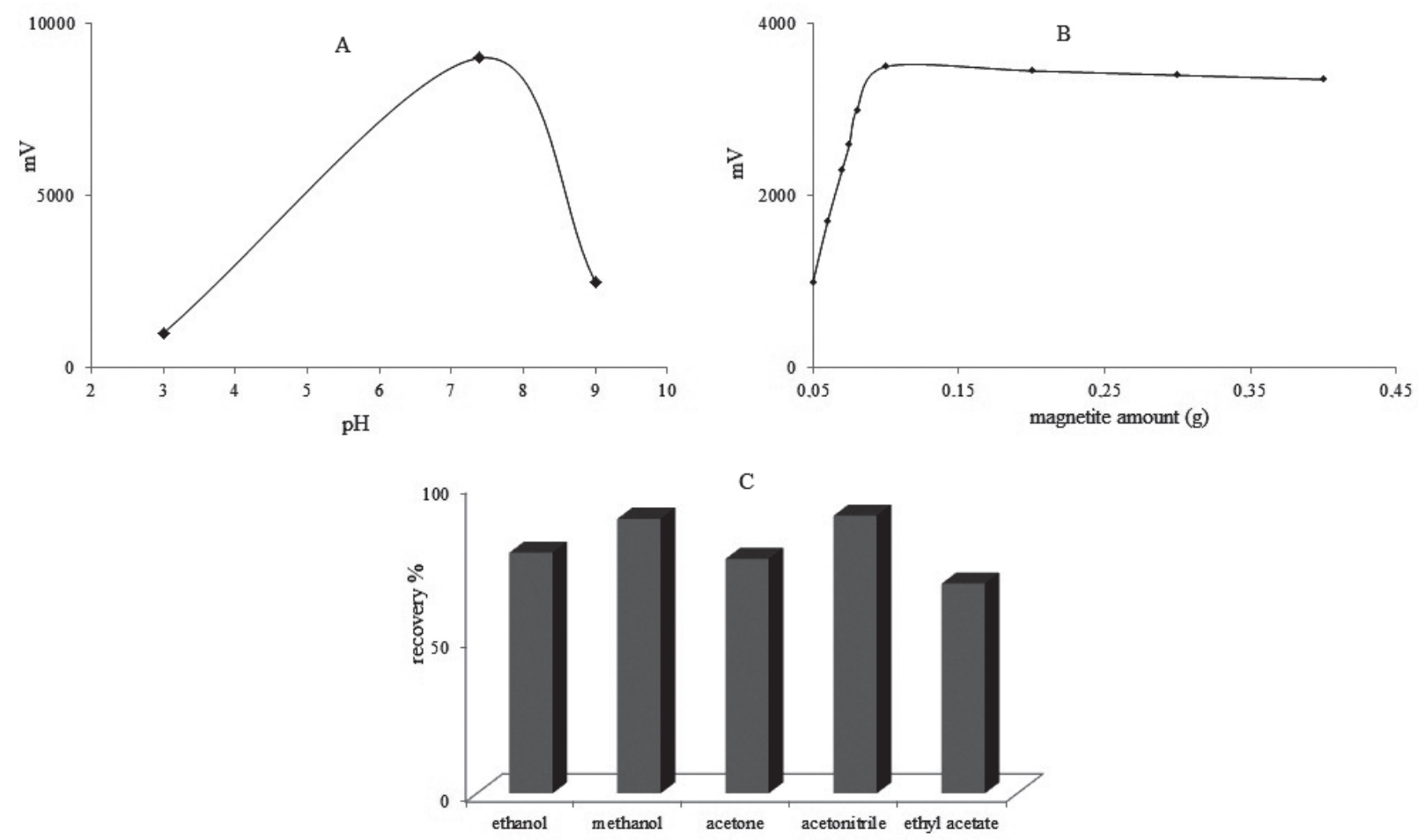

Figure 7. A) The effect of $\mathrm{pH}$ on the adsorption of $\mathrm{GMX}$ on $\mathrm{Fe}_{3} \mathrm{O}_{4}$ surfaces, B) The effect of $\mathrm{Fe}_{3} \mathrm{O}_{4}$ concentration on the adsorption of GMX on $\mathrm{Fe}_{3} \mathrm{O}_{4}$ surfaces $\mathrm{C}$ ) The recovery values of GMX with different desorption solvents.
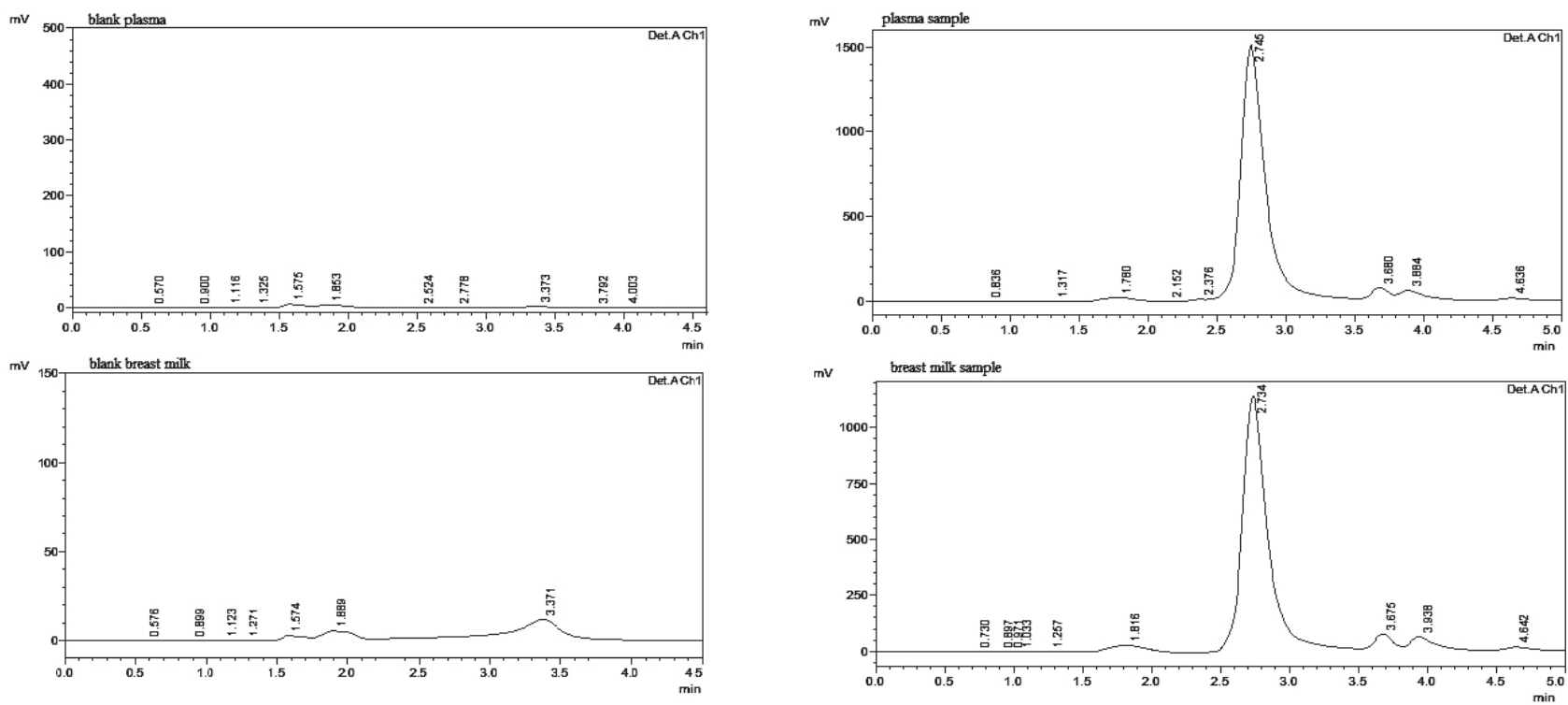

Figure 8. The chromatograms for blank and $10 \mu \mathrm{g} / \mathrm{mL}$ GMX in plasma and in breast milk. 


\subsection{Validation of the method}

The method was validated according to ICH Guideline criterion (25). For this purpose, parameters such as; accuracy and precision, linearity, sensitivity, robustness, stability were investigated.

\subsubsection{Accuracy and precision}

Accuracy and precision were determined by quantitation of QC samples at three concentration levels; $5,10,20 \mu \mathrm{g} / \mathrm{mL}$ as low, medium and high for both matrices. The accuracy was expressed by recovery and the precision by intraday and interday RSD values. The accuracy of the method was determined with standard addition method by spiking QC samples of standard drug solutions to plasma and milk including $10 \mu \mathrm{g} / \mathrm{mL}$ of GMX. Recovery values were calculated with the formula: Recovery $\%=[(\mathrm{Ct}-\mathrm{Cu})] / \mathrm{Ca}] \times 100$, where $\mathrm{Ct}$ is the total concentration of the analyte found; $\mathrm{Cu}$ is the concentration of the analyte present in the formulation; and $\mathrm{Ca}$ is the concentration of the added standard drug. Accordingly, recovery values were found as $\% 91.6$ and $\% 89.9$, the RSD of these results were 2.34 and 3.12 for plasma and milk, respectively. Table 2 shows the recovery and RSD values.

Table 1: Chromatographic system suitability parameters.

\begin{tabular}{|c|c|c|c|c|c|}
\hline sample matrix & capacity factor* & resolution* & HETP* & tailing factor* & asymmetry factor* \\
\hline plasma & 8.52 & 2.1 & 0.07 & 1.5 & 1.3 \\
\hline breast milk & 7.96 & 2.3 & 0.09 & 1.2 & 0.9 \\
\hline
\end{tabular}

*mean values of the parameters are mentioned

Table 2: Results of Recovery Studies by Standard Addition Method.

\begin{tabular}{|c|c|c|c|c|c|}
\hline & $\begin{array}{c}\text { Amount } \\
\mathbf{p r e s e n t} \\
(\boldsymbol{\mu g} / \mathbf{m L})\end{array}$ & $\begin{array}{c}\text { Amount } \\
\mathbf{a d d e d} \\
(\boldsymbol{\mu g} / \mathbf{m L})\end{array}$ & $\begin{array}{c}\text { Total amount } \\
\text { found } \\
(\mu \mathbf{g} / \mathbf{m L})\end{array}$ & $\begin{array}{c}\text { Recovery } \\
(\%)\end{array}$ & $\begin{array}{c}\text { RSD } \\
(\%)\end{array}$ \\
\hline & & 0.5 & 9.66 & 92.5 & 2.34 \\
\hline plasma & 10 & 10 & 18 & 90.0 & 1.82 \\
\hline & & 20 & 27.69 & 92.3 & 1.83 \\
\hline breast milk & 10 & 0.5 & 9.81 & 93.4 & 2.12 \\
\hline & & 10 & 17.72 & 88.6 & 3.12 \\
\hline
\end{tabular}

$\mathrm{n}=5$

Table 3: Precision of the method.

\begin{tabular}{|c|c|c|c|c|}
\hline & $\begin{array}{c}\text { Added } \\
\text { concentration } \\
(\boldsymbol{\mu g} / \mathbf{m L})\end{array}$ & $\begin{array}{c}\text { Found } \\
\text { concentration } \\
(\boldsymbol{\mu g} / \mathbf{m L}) \\
(\mathbf{M e a n} \pm \mathbf{S D})\end{array}$ & $\begin{array}{c}\text { RSD of } \\
\text { intraday } \\
\text { variation }\end{array}$ & $\begin{array}{c}\text { RSD of } \\
\text { interday } \\
\text { variation }\end{array}$ \\
\hline plasma & 5 & $5.54 \pm 0.28$ & 2.28 & 2.87 \\
\hline & 10 & $9.96 \pm 0.36$ & 3.22 & 3.43 \\
\hline & 20 & $19.7 \pm 0.54$ & 3.48 & 3.57 \\
\hline breast milk & 10 & $5.87 \pm 0.32$ & 3.12 & 3.27 \\
\hline & 20 & $11.12 \pm 0.65$ & 3.45 & 3.48 \\
\hline
\end{tabular}

$\mathrm{n}=5$

Table 4: Results of analytical parameters of the proposed method.

\begin{tabular}{|c|c|c|}
\hline Parameters & Plasma & Breast Milk \\
\hline Concentration range $^{a}(\mu \mathrm{g} / \boldsymbol{m L})$ & $0.5-30$ & $0.5-20$ \\
\hline Regression equation $^{b}$ & & \\
\hline Intercept $\pm \boldsymbol{S D}^{\boldsymbol{D}}$ & $0.5436 \pm 0.06$ & $0.6452 \pm 0.04$ \\
\hline Slope $\pm \boldsymbol{S D}$ & $1.3872 \pm 0.2$ & $0.8375 \pm 0.07$ \\
\hline Correlation coefficient $\left(\boldsymbol{r}^{2}\right)$ & 0.9997 & 0.9996 \\
\hline LOD $(\boldsymbol{\mu g} / \boldsymbol{m L})$ & 0.015 & 0.015 \\
\hline LOQ $(\boldsymbol{\mu g} / \mathbf{m L})$ & 0.5 & 0.5 \\
\hline
\end{tabular}

${ }^{\mathrm{a}} \mathrm{n}=6$

${ }^{\mathrm{b}} \mathrm{y}=\mathrm{xC}+\mathrm{b}$ where $\mathrm{C}$ is the concentration in $\mu \mathrm{g} \mathrm{ml}^{-1}$ and $\mathrm{y}$ is the peak area
To evaluate the precision of the method, intraday and interday repeatability were investigated by calculating the RSD. Five replicates of samples at each concentration were assayed on the same day for intraday and on three different days for interday precision. The RSD values of both intraday and interday assays were all less than $3.57 \%$. According to the results of these parameters the method shows good precision and accuracy. The results are shown in Table 3 .

\subsubsection{Linearity}

Calibration curves were obtained using linear least-squares regression analysis by plotting of peak areas of the derivatives versus the corresponding GMX concentrations. The equation of the calibration curve $(n=6)$ obtained from five points was: $y=1.3872 x+0.5436$ (correlation coefficient $=0.9997)$ and $\mathrm{y}=0.8375 \mathrm{x}+0.6452$ (correlation coefficient $=0.9996)$ for plasma and milk respectively, where y represents peak area of GMX and $\mathrm{x}$ represents the concentration of GMX. For plasma assays the method is linear over the range $0.5-30 \mu \mathrm{g} / \mathrm{mL}$ and for breast milk assays linearity is between $0.5-20 \mu \mathrm{g} / \mathrm{mL}$.

\subsubsection{Sensitivity}

The limit of detection (LOD) and limit of quantitation (LOQ) were determined using the formula: $\mathrm{LOD}$ or $\mathrm{LOQ}=\mathrm{kSDa} / \mathrm{b}$, where $\mathrm{k}=3$ for $\mathrm{LOD}$ and 10 for LOQ, SDa is the standard deviation of the intercept, and $\mathrm{b}$ is the slope. As mentioned in Table 4; LOD is 0.015 and LOQ is $0.5 \mu \mathrm{g} / \mathrm{mL}$ for both matrices.

\subsubsection{Robustnes}

Robustness was evaluated by making little modifications on the flowrate, column oven temperature and acetonitrile and water phase contents of the mobile phase. The mobile phase proportions were changed from (60:40 $\mathrm{v} / \mathrm{v}$ ) (acetonitrile-acidic solution) to 65:35 and 55:45; column temperature was changed from $40^{\circ} \mathrm{C}$ to $35^{\circ} \mathrm{C}$ and $45^{\circ} \mathrm{C}$; and the flow rate was changed from 1.3 to $0.7 \mathrm{~mL} / \mathrm{min}$. These changes had no significant effect on peak areas. Table 5 shows the robustness results.

\subsubsection{Stability}

The effects of freezing and thawing on GMX were studied using spiked 
QC samples of GMX into plasma and milk. The stability of GMX determined as $24 \mathrm{~h}$ and $6 \mathrm{~h}$ at room temperature for plasma and milk, respectively and at $-20^{\circ} \mathrm{C}$ for 4 weeks for both.

Table 5: Robustness of the method.

\begin{tabular}{|c|c|c|c|c|c|}
\hline \multirow[t]{2}{*}{ Condition } & \multirow[t]{2}{*}{ Value } & \multicolumn{2}{|c|}{ Recovery (\%) } & \multicolumn{2}{|c|}{$\underline{\operatorname{RSD}(\%)}$} \\
\hline & & plasma & breast milk & plasma & breast milk \\
\hline flow rate $\mathrm{mL} / \mathrm{min}$ & $\begin{array}{l}0.7 \\
1.3\end{array}$ & $\begin{array}{l}100.34 \\
100.56\end{array}$ & $\begin{array}{l}100.48 \\
100.77\end{array}$ & $\begin{array}{l}0.78 \\
1.25\end{array}$ & $\begin{array}{l}1.76 \\
1.34\end{array}$ \\
\hline $\begin{array}{c}\text { mobile phase ratio } \\
\text { (acetonitrile:aqueous } \\
\text { phase) }\end{array}$ & $\begin{array}{l}35: 65 \\
55: 45\end{array}$ & $\begin{array}{l}99.65 \\
97.73\end{array}$ & $\begin{array}{l}100.12 \\
100.48\end{array}$ & $\begin{array}{l}3.25 \\
2.58\end{array}$ & $\begin{array}{l}2.58 \\
2.74\end{array}$ \\
\hline column temperature & $\begin{array}{l}35 \\
45\end{array}$ & $\begin{array}{l}103.46 \\
101.37\end{array}$ & $\begin{array}{c}97.74 \\
100.54\end{array}$ & $\begin{array}{l}2.44 \\
1.52\end{array}$ & $\begin{array}{l}2.36 \\
3.32\end{array}$ \\
\hline
\end{tabular}

$\mathrm{n}=3$

\section{CONCLUSION}

In this study a new sample preparation and quantitation method was developed for the determination of GMX in human plasma and breast milk. Plasma and breast milk are complex biological matrices. Especially, milk has miscellaneous constituents; high protein, fat content and large amount of water. The extraction of target analytes in milk and also in plasma is a difficult process. In this study MSPE technique was used with $\mathrm{Fe}_{3} \mathrm{O}_{4}$ as adsorbent. The drug was extracted from both matrices with high recoveries in a short time and without a tedious procedure. As described above this technique is very simple and efficient and can be an alternative to LLE and SPE especially for drug analysis. MSPE application is the main advantageous part of the proposed method. Additionally, RP-HPLC part is also simple, doesn't require sophisticated equipment and operator like tandem MS which may not exist in routine laboratories. Also, mobile phase is not complex and gradient elution is not required, isocratic elution is sufficient and the retention time is very short at about $2.7 \mathrm{~min}$. The repeatability and accuracy of the method is very high.

\section{ACKNOWLEGMENTS}

The authors thank The Research Fund of Bezmialem Vakif University (Project No: 6.2015/20). The study protocol was approved by the Clinical Trials Ethics Commitee of Bezmialem Vakif University (B.30.2.BAV.0.05.05/379), Istanbul, Turkey.

\section{REFERENCES}

[1]. A. N. Gurpinar, E. Balkan, N. Kilic, I. Kiristioglu and H. Doğruyol, J. Int. Med. Res. 25 (1997), 302

[2]. P. M. Fleiss, J. Hum. Lact. 8(1) (1992), 7

[3]. J. K. Aronson, Fluoroquinolones Meyler's Side Effects of Drugs: The International Encyclopedia of Adverse Drug Reactions and Interactions, fifteenth ed., Elsevier, Amsterdam, 2006.

[4]. M. N. Lowe, H. M. Lamb, Drugs. 59 (2000), 1137

[5]. S. Malgorzata, K. Rafal, S. Jacek, J. Marek and B. Boguslaw, J. Chromatogr. A, 1272 (2013), 41

[6]. A. R. Rote, S. P. Pingle, J. Chromatogr. B, 877 (29) (2009), 3719
[7]. W. M. El-Koussi, N. N. Atia, A. M. Mahmoud and S. R. El-Shabouri, J. Chromatogr. B, 967, (2014), 98

[8]. E. Doyle, S. E. Fowles, D. F. McDonnell, S. A. White, J. Chromatogr. B, 746 (2000), 191

[9]. B. M. H. Al-Hadiya, A. A. Khady, G. A. E. Mostafa, Talanta, 83 (1) (2010), 110

[10]. O. Sagirli, S. Demirci and A. Onal, Luminescence, DOI 10.1002/bio.2901 (2015)

[11]. C. F. Poole, Trends Analyt. Chem. 22 (2003), 362

[12]. M. Wierucka and M. M. Biziuk, Trends in Analyt. Chem. 59 (2014), 50

[13]. R. Karami-Osboo, R. Miri, K. Javidnia, M. H Shojaee, and F. Kobarfard, Anal. Methods, 7 (2015), 1586

[14]. E. Behnam, Y. Yadollah, S. Shahram and T. Mohammad, Anal. Chim. Acta, 885, 98, (2015)

[15]. K. O. Rouhollah, M. Ramin, J. Katayoun, H. S.Mohammad and K. Farzad, Anal. Methods, 7, 1586, (2015)

[16]. Y. B. Luo, Z. G. Shi, Q. Gao and Y. Q. Feng, J. Chromatogr. A, 1218 , $1353,(2011)$

[17]. A. V. Herrera-Herrera, J.Hernández-Borges, M. M. Afonso, J. A Palenzuela and M. A. Rodríguez-Delgado, Talanta 116, 695, (2013)

[18]. A. Z. Hossein, T. Zeynab, Talanta 134 (1), 387, (2015)

[19]. M. Tang, Q. Wang, M. Jiang, L. Xu, Z. G. Shi, T. Zhang and Y. Liu, Talanta 130 (1), 427, (2014)

[20]. Y. Yadollah, F. Mohammad, J. Pharm. Anal., 4 (4), 279, (2014)

[21]. K. C. de Souza, G. F. Andrade, I. Vasconcelos, I. M. de Oliveira Viana, C. Fernandes and E.M. de Sousa, Mater. Sci. Eng. C Mater. Biol. Appl. 40 (1) $275,(2014)$

[22]. A. A. Ali, K. Sara, E. Homeira, S. Nafiseh and J. Niloofar, Int. J. Pharm. 494 (1), 102, (2015)

[23]. J. Mürbe, A. Rechtenbach and T. Töpfer, Mat. Chem. Phys. 110, 426, (2008),

[24]. A. P. Khandhar, R. M. Ferguson and K. M. Krishnan, J. Appl. Phys. 109 (7), 310, (2011)

[25]. The International Conference on Harmonisation (ICH), ICH Technical Requirements for Registration of Pharmaceuticals for Human Use on validation of analytical procedures Q2A. IFPM, 2005, Geneva. 